\title{
A SURGICAL TREATMENT OF ESSENTIAL HYPERTENSION
}

\author{
By IRVINE H. PAGE AND GEORGE J. HEUER \\ (From the Hospital of the Rockefeller Institute for Medical Research, and the Surgical . \\ Department, New York Hospital and Cornell Medical College, New York)
}

(Received for publication August 3, 1934)

Evidence of varied nature indicates that the arterioles of the splanchnic region are constricted in patients suffering from essential hypertension, and that this may be an important factor in maintaining the pressure at an elevated level. Interruption, by surgical means, of nerves carrying effector impulses to this region would therefore appear to be a logical therapeutic procedure.

Section of the anterior nerve roots close to the cord seems a method which will surely intercept both the motor and sympathetic innervation. It is furthermore desirable that denervation be as complete as possible without interfering with vital functions. Anatomical considerations suggest that this can best be accomplished by section of the anterior roots from the sixth thoracic segment to, and including, the second lumbar.

The sixth to the twelfth thoracic motor nerves innervate the intercostal muscles and the seventh to first lumbar nerves supply the abdominal musculature. Part of the supply to the flexor muscles of the hip is derived from the first and second lumbar nerves. The first lumbar root contributes branches to the ileoinguinal and ileohypogastric nerves, and both the first and second roots send fibers to the genito-femoral. The lateral cutaneous nerves receive fibers from the first, second and third lumbar roots.

There is some difference of opinion as to the anatomy of the sympathetic system in the thoracico-lumbar region. All of the anterior nerve roots contribute to the innervation of the cutaneous vessels, pilomotor muscles and sweat glands. The major splanchnic nerves are derived from the fifth to the tenth thoracic segment, and the minor splanchnic from the ninth and tenth or the tenth to twelfth roots. These nerves join the celiac plexus. In this manner connection is established with the stomach, liver, adrenals, pancreas, intestine and kidneys. Section of the sixth thoracic to the second lumbar roots, therefore, partially interrupts not only the motor nerve supply of the $a b$ - dominal wall but the sympathetic supply of most of the abdominal viscera, except the colon, rectum, bladder and genital organs. The vagus and phrenic nerves and the intrinsic nerve supply remain intact to innervate the viscera. The inferior mesenteric ganglion also remains intact except for loss of some fibers from the second lumbar root.

Adson and Brown (1) (1934) were the first to suggest and perform the operation as outlined. By this procedure they hoped (1) to remove the sympathetic innervation of sufficient arteries to modify arterial responses, (2) thoroughly to denervate the suprarenal glands, and (3) to remove the effects of intra-abdominal tension. They report a case of early malignant hypertension in a woman 29 years of age who had had high blood pressure for at least 18 months. The blood pressure in the recumbent position varied from 150 to 200 systolic and from 100 to 150 diastolic. The range following operation was from 155 to 195 systolic and from 100 to 150 diastolic. After operation no visible sweating was found below the level of the epigastric notch anteriorly or below the angle of the scapulae posteriorly. There was no difference in the amount of phenolsulphonphthalein excreted whether the patient was standing or recumbent. Evidently considerable sclerosis of the vessels was present in this case. After operation the retinal vessels remained narrowed. Retinitis was, however, less active than on admission. The response to Brown's test of pressor response to cold showed that following operation there was a significant decrease in the maximum rise in blood pressure. While the operation did not lower the systemic blood pressure level as much as might have been hoped for, it was believed that this was due to structural changes in the blood vessels.

It therefore seemed to us desirable to select a case in which the vascular tree was still flexible and yet one in which the hypertension was a potential source of grave danger to life. 
Hospital No. 8990. The patient, a 23 year old Jewish girl, complained of fatigue and restlessness for a period of at least one year and a half. She had had good health up to the time of her present illness. Temperamentally, however, she was excessively excitable and unstable. Her friends found her a "difficult" person.

A chance physical examination showed that her blood pressure was over $200 \mathrm{~mm}$. Hg. Until a few months ago she was symptom-free except for the feeling of excessive fatigue. Headaches were frequent and she suffered from palpitation and dull pains over the precordium. At night her ankles swelled.

The patient was a well developed, highly nervous girl. She had advanced acne vulgaris over her face, chest, and back. The hair distribution was normal. The fundus examination demonstrated that the nerve head was hyperemic, the arterioles were slightly constricted and the veins dilated. There were no retinal hemorrhages or exudates. The tonsils were buried and ragged and the thyroid gland was not enlarged. The heart measurements were as follows: M.L. $=8.3 \mathrm{~cm}$., M.R. $=4.6 \mathrm{~cm}$. The chest diameter was $23 \mathrm{~cm}$. The cardiac sounds were - of good quality and $A_{2}$ and $P_{2}$ were slightly accentuated. The peripheral vessels were not tortuous or thickened. The blood pressure was $200 / 140 \mathrm{~mm}$. $\mathrm{Hg}$. The kidneys were palpable but not enlarged. The superficial and deep reflexes were hyperactive. The hands and feet were cold and perspired freely.

This girl seemed to be suffering from essential hypertension of relatively short duration. Her temperament undoubtedly greatly intensified the disease as we had occasion to observe on many occasions. Her vascular system was still flexible as evidenced by the facts that amyl nitrate, mecholin (acetyl $\beta$-methyl cholin) and postural changes produced marked diminution in her blood pressure. There was also neither palpable sclerosis of her peripheral vessels nor visible changes, except constriction in her retinal arterioles. Cardiac decompensation was evident under strain, for edema of her ankles appeared only after a day's work.

The patient was confined to bed in the hospital and the level of the blood pressure measured at 9:30 every morning. Ten days after admission sodium thiocyanate was administered over a period of 20 days. It was necessary also to give chloral hydrate ( 0.5 gram t.i.d.) and amytal at night. A graphic chart (Figure 1) has been prepared to show the course of the patient while in the hospital.

Thiocyanate treatment apparently caused the level of the blood pressure to fall markedly but, on discontinuing the drug, it rose to its original level. After about ten weeks of strict bed rest it was evident that the blood pressure would not fall more than it had. It varied from a maximum of $192 / 134$ to $162 / 108 \mathrm{~mm}$. Hg. Since the patient showed no improvement it was our belief that radical surgical intervention was justifiable.

Surgical procedure. The operation was performed May 11, 1934, under ether anesthesia. It consisted of the exposure and removal of the laminae corresponding with the sixth thoracic to the second lumbar segments

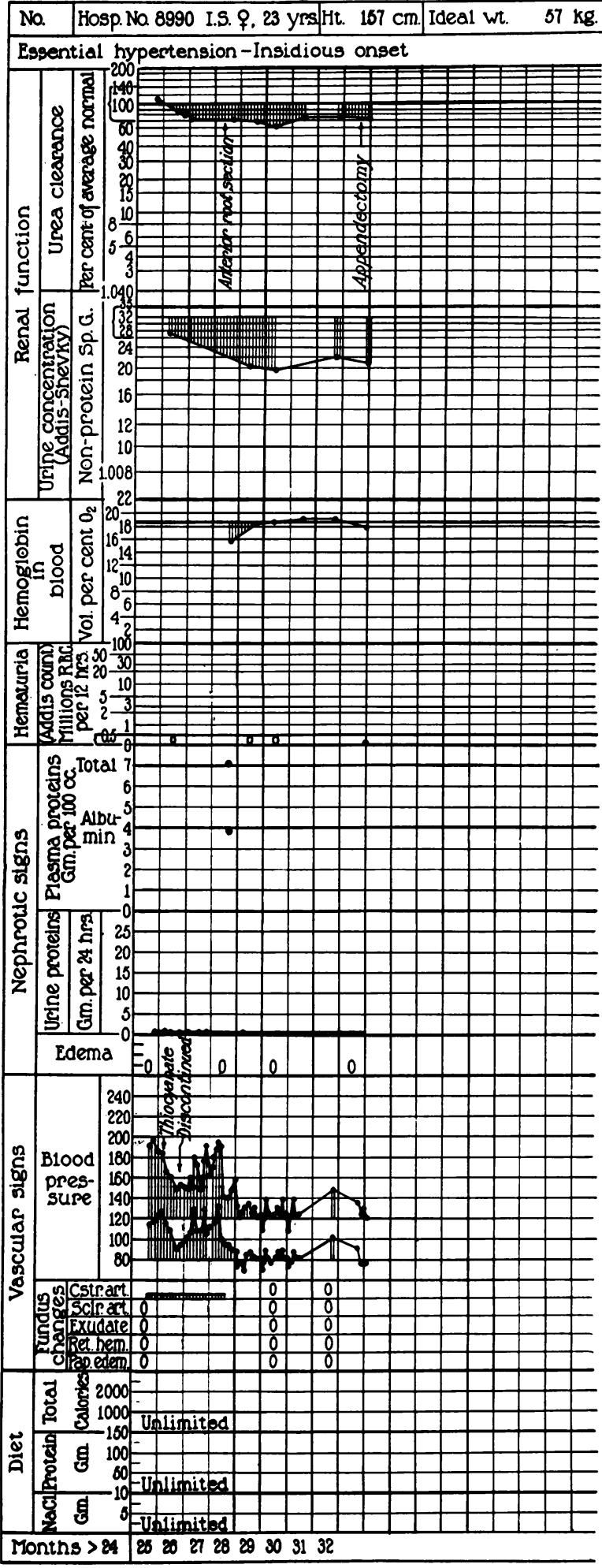

FIg. 1. 
inclusive; and the incision of the dura mater so as to expose the spinal cord. With an appropriate instrument each pair of anterior nerve roots was separated from the spinal cord as it coursed along this structure and divided approximately midway between its point of origin and its union with the posterior roots. Silver clips were placed across several roots, the division of which was associated with slight hemorrhage. After completing the division of the roots the wound was closed throughout with silk. The operation required three hours. The pulse during operation varied between 110 and 90 .

Recovery from the operation was uneventful. The blood pressure fell rapidly and progressively to a level that was nearly normal. Especially striking was the fall in diastolic pressure. For the first week after operation the patient had moderate difficulty in evacuating her bowels. This was remedied by use of enemata. The abdominal muscles were completely paralyzed. Although relaxed, when the patient stood up, there was almost no "pot belly." An abdominal binder was not found necessary. She soon learned how to manage the motion of her trunk without the use of the abdominal musculature.

There was steady improvement in the patient's strength but her emotional volatility continued unabated. Her headaches, palpitations and precordial pain, however, disappeared.

\section{Laboratory examinations before and after opcration}

The renal function, as measured by the urea clearance test, was found to be normal on six occasions before operation. Nor did it change significantly following operation. The ability of the kidneys to concentrate was also not markedly impaired though the maximum non-protein specific gravity ${ }^{1}$ fell from 1.027 to 1.019 , measurements being made on a 12 -hour specimen voided at the end of 24 hours without fluids. Neither before nor after operation was there an increase in the number of red blood cells or casts counted in Addis sediment test specimens of urine. Sugar was not found in the urine.

The plasma proteins were normal as was the hemoglobin. The latter fell slightly following operation but quickly returned to normal.

The basal metabolic rate was normal both before and after operation.

An electrocardiogram taken about two months before operation showed the following characteristics: $\mathrm{T}$ waves +++ , conduction time $0.17 \mathrm{sec}-$ onds, $\mathrm{R}_{3}$, split, low voltage and normal rhythm. Another record taken two months after operation showed: $\mathrm{T}$ waves ++ - conduction time 0.16 , $R_{\text {:: }}$ split and normal rhythm.

A muscle biopsy removed from the lumbar

${ }^{1}$ Obtained by subtracting 0.003 from the total specific gravity for each one per cent of protein (6).

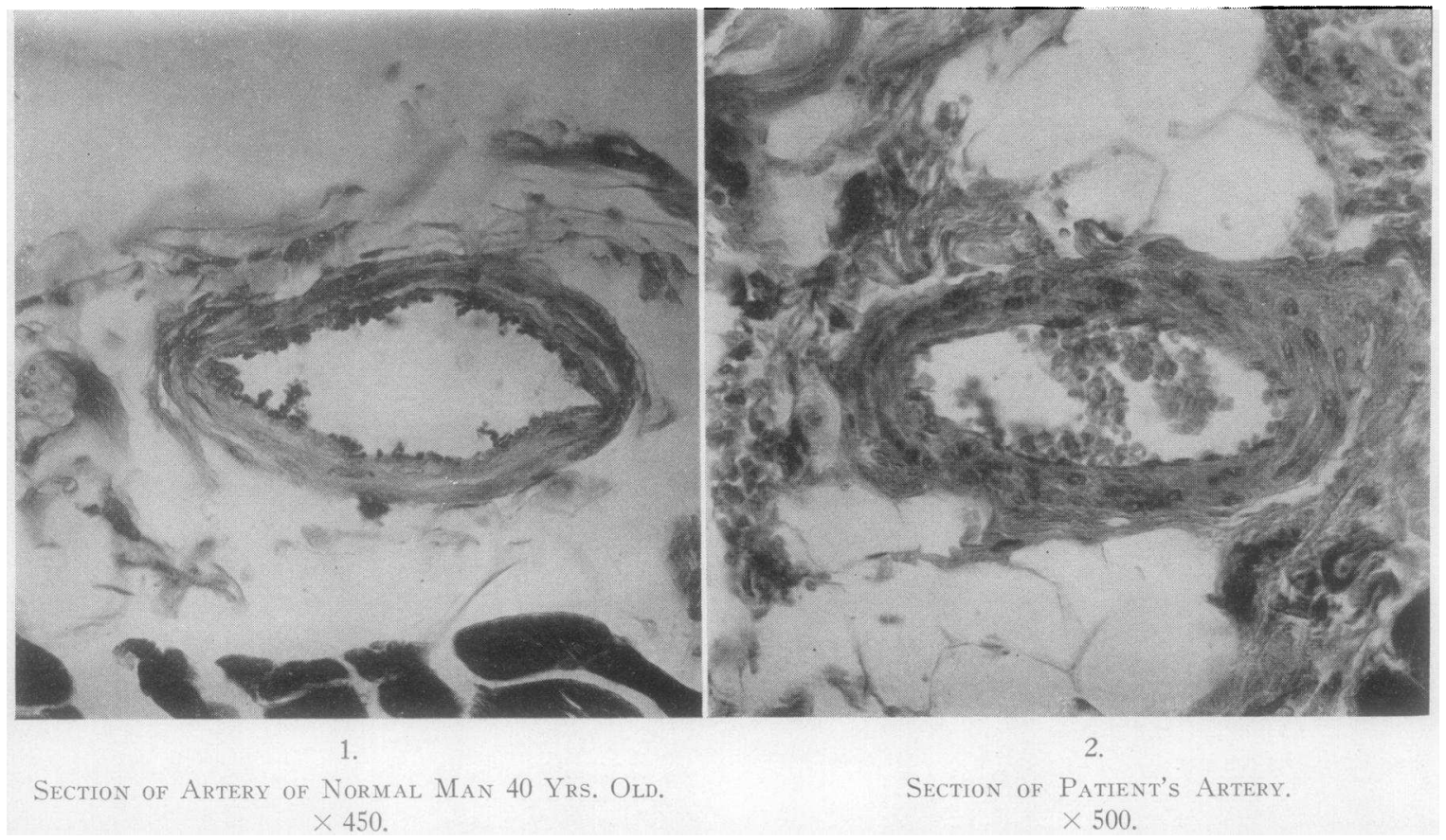

Fili. 2. 
muscle during operation showed, according to Dr. C. P. Rhoads, that moderate but definite intimal thickening had taken place in the arterioles. (See Figure 2.)

Dr. William Lewis measured the minute volume output of this patient 26 days after operation by the acetylene procedure (Grollman et al. (2)). The following results were obtained:

Cardiac output, liters per minute $=4.1$.

Arteriovenous oxygen difference per liter blood $=53.4 \mathrm{cc}$.

Cardiac output, liters per minute per square meter of body surface $=2.9$.

Basal metabolic rate $=+7$ per cent (Dubois standard).

The level of minute volume output is higher than the average normal (2.2 \pm 10 per cent). Since only one determination was made it should not be considered as constantly elevated. It seems certain at least that it is not reduced below normal level as the result of operation.

The content of lipid in the plasma was ascertained before and after operation by the method of Kirk, Page and Van Slyke (1934). level by anterior nerve root section. The blood pressure has remained at a level which is almost normal for seven months, in spite of the fact that the patient was allowed to go about the hospital wards without restriction. Emotional excitement caused the pressure to rise but seldom did it exceed $160 \mathrm{~mm}$. Hg. Nor did it remain persistently elevated but rather quickly fell to its original level.

The ability of the kidneys to excrete urea, as measured by the urea clearance test, was unaltered as the result of almost complete denervation resulting from rhizotomy. It is interesting to note that no change in efficiency of the kidneys resulted even though a marked fall in blood pressure occurred. This corroborates the observation of Page (1934) that the efficiency of the kidneys in cases of essential hypertension and nephritis is not directly dependent on the level of systemic blood pressure. The power of the kidneys to concentrate urine was somewhat reduced.

Hemoglobin, plasma proteins, urine proteins, urine sugar and plasma lipids were not appreciably altered following operation. The basal metabolic rate and cardiac output both remained

TABLE I

Lipid content of plasma during fasting

\begin{tabular}{|c|c|c|c|c|c|c|c|c|}
\hline Date & $\begin{array}{l}\text { Total } \\
\text { lipid } \\
\text { carbon }\end{array}$ & $\begin{array}{l}\text { Total } \\
\text { cho- } \\
\text { lesterol }\end{array}$ & $\begin{array}{c}\text { Free } \\
\text { cho- } \\
\text { lesterol }\end{array}$ & $\begin{array}{c}\text { Lipid } \\
\text { amino } \\
\text { nitrogen }\end{array}$ & $\begin{array}{c}\text { Lipid } \\
\text { nitro- } \\
\text { gen }\end{array}$ & $\begin{array}{c}\text { Lipid } \\
\text { phos- } \\
\text { phorus }\end{array}$ & $\begin{array}{l}\text { Total } \\
\text { phos- } \\
\text { phatidef }\end{array}$ & $\begin{array}{l}\text { "Ceph- } \\
\text { alin" } \ddagger\end{array}$ \\
\hline & $\begin{array}{c}\text { mgm. per } \\
100 \text { cc. }\end{array}$ & $\begin{array}{l}\text { mgm. per } \\
100 \text { cc. }\end{array}$ & $\begin{array}{l}\text { mgm. per } \\
100 \text { cc. }\end{array}$ & $\begin{array}{l}\text { mgm. per } \\
100 \text { cc. }\end{array}$ & $\begin{array}{l}\text { mgm. per } \\
100 \mathrm{cc} .\end{array}$ & $\begin{array}{c}\text { mgm. per } \\
100 \text { cc. }\end{array}$ & $\begin{array}{c}\text { mgm. per } \\
100 \text { cc. }\end{array}$ & $\begin{array}{l}\text { mgm. per } \\
100 \text { ce. }\end{array}$ \\
\hline $\begin{array}{l}\text { March } 6 \text {, before operation . . . . . . . } \\
\text { June } 22 \text {, after operation } \ldots \ldots \ldots \ldots \\
\text { Normal average values for young men }\end{array}$ & $\begin{array}{l}479 \\
528 \\
528\end{array}$ & $\begin{array}{l}192 \\
241 \\
212\end{array}$ & $\begin{array}{l}72.6 \\
88.1 \\
83\end{array}$ & $\begin{array}{l}2.22 \\
6.33 \\
3.1\end{array}$ & $\begin{array}{r}6.14 \\
20.4 \\
9.7\end{array}$ & $\begin{array}{l}5.47 \\
8.65 \\
6.3\end{array}$ & $\begin{array}{l}129 \\
202 \\
147\end{array}$ & $\begin{array}{l}118 \\
235 \\
174\end{array}$ \\
\hline
\end{tabular}

$\dagger$ Total phosphatide calculated from lipid phosphorus. ‡ "Cephalin" calculated from lipid amino nitrogen.

According to the values found by Page, Kirk and Van Slyke (1935) to be normal for young men, these results may be considered to fall within normal limits. The lipid amino nitrogen or " cephalin" value found after operation is slightly higher than normal.

\section{DISCUSSION}

Although the level of arterial blood pressure in this patient was high and tended to remain so, nevertheless the vascular system was flexible. It is our belief that as a consequence of this flexibility it was possible to reduce the blood pressure normal. There was no increase above normal of the excretion of red blood cells in the urine.

\section{CONCLUSIONS}

1. Section of the anterior nerve roots from the 6 th thoracic to the $2 \mathrm{~d}$ lumbar segment has been performed in a young girl suffering from persistently elevated arterial blood pressure. Anatomical and physiological evidence indicated that her vascular system was yet flexible.

2. The blood pressure level quickly fell to normal, and has remained normal for seven months.

3. Denervation of the kidneys resulting from 
the operation did not alter their power to excrete urea but there was slight loss in ability to concentrate urine. The kidneys were as efficient when the blood pressure was reduced to normal as when it had been elevated. No increase occurred in the number of red blood cells excreted in the urine.

4. In spite of the fact that the blood pressure fell to normal, there was no change in the subjective feeling of the patient except that headaches, palpitation, and precordial pain disappeared.

5. No significant alterations occurred in the hemoglobin, and plasma proteins. The basal metabolism and cardiac output also were normal. Electrocardiographic records taken before and after operation showed no change from normal.

6. Determinations were made of total lipid, total and free cholesterol, lipid amino nitrogen, total lipid nitrogen and lipid phosphorus in the blood plasma both. before operation, when the blood pressure was elevated, and after when it was normal. Except for slight rise in lipid amino nitro- gen and total lipid nitrogen, following operation, the changes were insignificant.

\section{BIBLIOGRAPHY}

1. Adson, A. W., and Brown, G. E., Malignant hypertension. Report of case treated by bilateral section of anterior spinal nerve roots from the sixth thoracic to the second lumbar inclusive. J. A. M. A., 1934, 102, 1115.

2. Grollman, A., Friedman, B., Clark, G., and Harrison, T. R., Studies in congestive heart failure. XXIII. A critical study of methods for determining the cardiac output in patients with cardiac disease. J. Clin. Invest., 1933, 12, 751.

3. Kirk, E., Page, I. H., and Van Slyke, D. D., Gasometric micro-determination of lipids in plasma, blood cells and tissues. J. Biol. Chem., 1934, 106, 203.

4. Page, I. H., Kirk, E., and Van Slyke, D. D., Plasma lipids in normal persons and in patients suffering from essential hypertension, malignant hypertension and Bright's disease. 1935. (In press.)

5. Page, I. H., The effect on renal efficiency of lowering arterial blood pressure in cases of essential hypertension and nephritis. J. Clin. Invest., 1934, 13, 909.

6. Lashmet, F. H., and Newburgh, L. H., An improved concentration test of renal function. J. A. M. A., 1932, 99, 1396. 